\title{
Antagonistic Properties of Methanol Extract of Elaeocarpus sphaericus Leaves against in vitro Growth, Germ Tube Formation, Adhesion and Biofilm of Candida Species
}

P. GUPTA, A. RASTOGI, S. JOSHI, A. BHARDWAJ'1 K. MISRA ${ }^{1}$ AND N. KUMAR*

Department of Biotechnology, Graphic Era (Deemed To Be University), 566/6, Bell Road, Clement Town, Dehradun-248 002, ${ }^{1}$ Department of Biochemical Sciences, Defence Institute of Physiology and Allied Sciences, Lucknow Road, Timarpur, Delhi-110 054, India

Gupta et al.: Anticandida properties of Elaeocarpus sphaericus Roxb

The extracts of Elaeocarpus sphaericus (Roxb.) have shown antimicrobial activities against many pathogenic microbes including fungi. However, the effects of Elaeocarpus sphaericus have not been investigated against key virulence attributes of Candida. In the present study, methanol extract of Elaeocarpus sphaericus leaves was analysed against planktonic cells, hyphal growth, adhesion and biofilm formation of two most important fungal pathogens, Candida albicans and Candida glabrata. Methanol extract of Elaeocarpus sphaericus leaves was prepared by pressurized liquid extraction method. Inhibitory concentration of methanol extract of Elaeocarpus sphaericus leaves for both pathogens was determined by broth microdilution assay. Germ tube formation assay was performed to study the effect of the extract on hyphal transition. Effect of methanol extract of Elaeocarpus sphaericus leaves on adhesion and biofilm formation was investigated in microtiter 
plate using 2,3-bis(2-methoxy-4-nitro-sulfophenyl)-2H-tetrazolium-5-carboxanilide reduction assay. $\mathrm{IC}_{50}$ values of the extract for Candida albicans and Candida glabrata were found between $0.625-1.25 \mathrm{mg} / \mathrm{ml}$. Serum-induced germ tube development in Candida albicans was inhibited in presence of $5 \mathrm{mg} / \mathrm{ml} \mathrm{methanol}$ extract. The extract remarkably inhibited in vitro adhesion and biofilm formation by Candida albicans and Candida glabrata in microtiter plates. The results of this study showed anticandida potential of methanol extract of Elaeocarpus sphaericus leaves.

Key words: Elaeocarpus sphaericus, Candida albicans, Candida glabrata, biofilm, adhesion, germ tube, XTT assay, broth microdilution

Candida is an opportunistic, commensal, human fungal pathogen, which causes infections ranging from superficial mucosal to deep invasive including systemic candidiasis, in immune-compromised patients ${ }^{[1,2]}$. Candida albicans and C. glabrata are two most common pathogenic species found in oral cavity, gastrointestinal tract and reproductive system of healthy humans ${ }^{[3]}$. Instances of Candida pathogenicity and virulence have been increased in the last two decades ${ }^{[4]}$. The trend of Candida caused infection is now shifting from albicans to non-albicans Candida species worldwide ${ }^{[5]}$. According to the report of Center for Disease Control, USA on antibiotic resistance threats in the United States (2013), Candida is developing resistance to available antibiotics and rate of occurrence of C. glabrata in clinical isolates is increasing alarmingly ${ }^{[6]}$. The ability of hyphal transition, adhesion and biofilm formation over biotic and abiotic surfaces (including various prosthetic, indwelling devices) contributes to the virulence and pathogenicity of Candid $a^{[7,8]}$. Reports on increasing resistance to existing drugs in the clinical isolates of the Candida and toxicity of the existing drugs have justified the need of a natural product with antifungal properties ${ }^{[9]}$. Plants have always been an important source of medicines for human beings since time immemorial ${ }^{[10,11]}$. Plant-derived products are deriving the interest of researchers towards their use in development of new generation drugs ${ }^{[12,13]}$. Hundreds of plant extracts have been reported so far to have anticandida properties ${ }^{[14]}$. Elaeocarpus sphaericus is a well-known plant with medicinal value from thousands of years in the Ayurveda, Unani and Siddha. Earlier, antimicrobial properties of the leaves of E. sphaericus have been investigated ${ }^{[15,16]}$. Few plant extracts have been reported to be effective against Candida biofilm also $^{[17-19]}$.

In the present study, the effect of methanol extract of E. sphaericus leaves prepared through pressurized

*Address for correspondence E-mail: navinbajpai@gmail.com liquid extraction was analysed against key virulence attributes of $C$. albicans and C. glabrata such as in vitro growth, germ tube formation, adhesion and biofilm formation.

C. albicans (strain SC5314) and C. glabrata (strains MTCC 3019) were obtained from the Institute of Microbial Technology (CSIR), Chandigarh, India. Strains were maintained on yeast-peptone-dextrose (YPD) agar plates and incubated at $37^{\circ}$. After $24 \mathrm{~h}$, colonies were picked from the surface of agar plate and inoculated into YPD broth. YPD was prepared by dissolving individual components (yeast extract $1 \%$, agar $2 \%$, peptone $2 \%$ and dextrose $2 \%$; procured from HiMedia) in distilled water. Biofilm and adhesion assays were performed in yeast nitrogen base (YNB) medium ( $0.67 \%$ YNB w/o amino acids with ammonium sulphate supplemented with $2 \%$ dextrose, $\mathrm{pH}$ 7.0; procured from Becton Dickinson) on the surface of pre-sterilized, polystyrene, flat bottomed 96-well microtiter plates (Make-HiMedia). Purpurine, amphotericin B (amp B), menadione and 2,3-bis (2-methoxy-4-nitro-sulfophenyl)-2H-tetrazolium-5carboxanilide (XTT) were purchased from HiMedia.

The leaves of E. sphaericus Roxb. were collected from Dhradun and verified in the Department of Botany, HNBG University, Srinagar and a specimen sample was submitted to the herbarium of the University, vide voucher specimen number GUH20720. The methanol extract of leaves of E. sphaericus was prepared through the method of pressurized liquid extraction with an aim to get phenolic-rich extract ${ }^{[20,21]}$. Briefly, dried

This is an open access article distributed under the terms of the Creative Commons Attribution-NonCommercial-ShareAlike 3.0 License, which allows others to remix, tweak, and build upon the work non-commercially, as long as the author is credited and the new creations are licensed under the identical terms

Accepted 10 July 2018

Revised 03 December 2017

Received 22 March 2017

Indian J Pharm Sci 2018;80(5):949-954 
leaves were crushed to a fine powder and pressurized liquid extraction was performed in accelerated solvent extraction system equipped with a solvent controller unit (ASE350, DIONEX and Corporation Sunnyvale, CA, USA $)^{[22]}$. Powdered sample $(10 \mathrm{~g})$ was loaded into the extraction cell of ASE with an equal amount of silica powder in 1:1 ratio. Absolute methanol was used as the solvent. A pressure of 1500 psi was applied and for each extraction, five cycles (5 min each) were performed. Evaporation of solvents was done in a rotavapor (Rota Vapor124, Bucchi, and Flawil, Switzerland). After evaporation, the plant extract was lyophilized and stored at $4^{\circ}$ until further use. Dilutions of extract were prepared in $25 \%$ dimethyl sulfoxide (DMSO) before use. Throughout this communication, methanol extract of E. sphaericus Roxb. was referred to as MES.

Inhibitory concentrations of MES against $C$. albicans and C. glabrata were determined using M27-A2 guidelines $^{[23]}$. Briefly, log phase culture in YNB broth was inoculated in 96-well round bottom plant containing YNB medium with different dilutions of the extract (from 0.156 to $5 \mathrm{mg} / \mathrm{ml}$ ). Final volume of assay system was kept $200 \mu 1$ per well. The plates were covered with lid and were incubated at $35^{\circ}$ for $48 \mathrm{~h}$. The growth was measured by taking absorbance at $600 \mathrm{~nm}$.

Germ tube formation was induced in a medium containing new born calf serum $(10 \% \mathrm{v} / \mathrm{v})$ as an inducer of germ tube formation ${ }^{[24]}$. Overnight culture of C. albicans was diluted in fresh YPD broth and different components were mixed to make the volume $1.0 \mathrm{ml}$ in each tube. Germ tube formation was induced by $10 \%$ serum in two tubes, with and without MES $(5 \mathrm{mg} / \mathrm{ml})$. Two uninduced tubes, with and without MES, were kept as controls. All tubes were incubated at $37^{\circ}$ with shaking for $4 \mathrm{~h}$. After incubation cells were observed microscopically under phage contrast microscope (Olympus). Samples were analysed by negative stain before being photographed at 40X. Since $C$. glabrata does not form germ tube, therefore only $C$. albicans was used.

The effect of MES on adhesion of $C$. albicans and C. glabrata was observed in a 96-well microplate (polystyrene surface) ${ }^{[25]}$. Log phase cell suspension was prepared in YNB medium at a concentration of $1 \times 10^{7}$ cells $/ \mathrm{ml}$. Hundred microliters of cell suspension was added to each well along with $100 \mu$ of media containing different concentration of MES in a range of
0.156 to $5 \mathrm{mg} / \mathrm{ml}$. Cells were allowed to adhere on the surface in presence of plant extract. Wells without MES were kept as control. The plates were incubated for $90 \mathrm{~min}$ at $37^{\circ}$ at $100 \mathrm{rpm}$ in an orbital shaker for adhesion. After incubation, wells were washed with phosphate buffer solution (PBS) to remove any planktonic cells. Density of adherence in each well was determined using XTT reduction assay, and percent metabolic activity was calculated to determine cell adherence. The effect of MES on in vitro adhesion is shown in terms of relative metabolic activity (RMA), which is percent metabolic activity at particular concentration of MES, assuming $100 \%$ metabolic activity of the sample without MES.

Cells were allowed to develop biofilm on pre-sterilized polystyrene surface of 96-well microplate as per standard methodologies ${ }^{[26]}$. Briefly, log phase cells were suspended in PBS at a concentration of $1 \times 10^{7}$ cells $/ \mathrm{ml}$. Hundred microlitres of cell suspension was added to each well and plates were incubated at $37^{\circ}$ for $90 \mathrm{~min}$ at $100 \mathrm{rpm}$ in orbital shaker to allow attachment of cells on the surface. The wells were washed twice with PBS to remove non-adhered cells and the plates were observed under inverted light microscope for observing cell adherence. Afterwards, $200 \mu \mathrm{l}$ of YNB medium with different concentrations of MES was added to each well, including one without MES (control) and plates were incubated at $37^{\circ}$ for $48 \mathrm{~h}$. After incubation, wells were washed twice with PBS to remove any planktonic cells and biofilm was observed using an inverted light microscope. Quantification of biofilm was performed by XTT reduction assay with slight modifications. The effect of MES on biofilm activity is shown in terms of RMA as mentioned above in adhesion assay.

XTT reduction assay was performed to measure the adhesion and biofilm development ${ }^{[26]}$. XTT measures the activity of mitochondrial dehydrogenase. The XTT solution $(1 \mathrm{mg} / \mathrm{ml})$ was prepared in PBS and then syringe filtered $(0.22 \mu \mathrm{m}$ pore size $)$. Menadione solution $(0.4 \mathrm{mM})$ was prepared in acetone. Prior to use, menadione was added to XTT to a final concentration of $4 \mu \mathrm{M}$. XTT-menadione solution (20:1) was added to each well and final volume of assay system was maintained by PBS at $200 \mu 1$. The plates were covered with lid and incubated in dark for $2 \mathrm{~h}$ at $37^{\circ}$. After incubation, supernatant $(100 \mu \mathrm{l})$ was transferred to another fresh 96-well plate and optical density was measured at $450 \mathrm{~nm}$ wavelength. 
All experiments were performed in triplicate and values presented are the average of three values along with standard deviation.

Emergence of pathogenic drug resistant strain is a complex problem today and Candida also belongs to the same category ${ }^{[6]}$. The virulence and pathogenesis of Candida is associated with its morphology and immune state of host ${ }^{[27]}$. The yeast to hypha transition in C. albicans is responsible for its pathogenicity. In this study, MES has shown complete inhibition of growth, hyphal transition, adhesion and biofilm development.

Phytochemical analyses of MES showed the presence of high contents of phenolics and flavonoids ${ }^{[16]}$. Phenols are organic compounds having substituted phenolic ring. Their antimicrobial activity is relative to the number and position of hydroxyl groups on the phenol group. These compounds produce their effect by inhibiting enzyme through oxidized compounds ${ }^{[28-32]}$. Flavonoids are the hydroxylated phenolic substances which are produced in plants during microbial infection and hence it is not surprising that they are potential inhibitors of microbial growth and work as antimicrobial agent either by making complexes with extracellular and soluble proteins or by disrupting fungal cell wall because of their lipophilic nature ${ }^{[33,34]}$.

The effect of MES on planktonic growth of C. albicans and C. glabrata was determined by broth microdilution assay at different concentrations of the extract (fig. 1). As shown in fig. 1, growth of both pathogens decreased with the increasing concentration of the extract. Correlation coefficients, $\left(\mathrm{R}^{2}\right)$ were 0.951 and 0.977 for C. albicans and C. glabrata, respectively. $\mathrm{IC}_{50}$ values (concentration required for $50 \%$ growth inhibition) of MES for C. albicans and C. glabrata were found to lie between $0.625-1.25 \mathrm{mg} / \mathrm{ml}$. At $5 \mathrm{mg} / \mathrm{ml}$ of MES, both species were completely inhibited. In a previous study, minimum inhibitory concentration (MIC) of E. sphaericus leaves and dried fruit, against Candida, have been reported to be $1.5 \mathrm{mg} / \mathrm{ml}$ for chloroform extract and $4 \mathrm{mg} / \mathrm{ml}$ for ethanol extract in the broth microdilution method ${ }^{[35]}$. In another study, MIC of aqueous extract of E. sphaericus leaves was found to be $1 \mathrm{mg} / \mathrm{ml}$ against $C$. albicans in the agar well diffusion assay ${ }^{[15]}$. In the present study, MES showed better inhibition of Candida than extracts prepared in previous studies, probably due to the presence of high phenolics.

Effect of MES on germ tube formation was studied for $C$. albicans only because C. glabrata does not form true hyphae. As shown in fig. 2, serum-induced formation of germ tube was inhibited in the presence of $5 \mathrm{mg} / \mathrm{ml}$ MES (fig. 2), whereas serum-induced germ tube sample without extract showed significant germ tube formation (fig. 2). Uninduced controls did not show any germ tube induction (fig. 2). This inhibition may be due to presence of flavonoids and antioxidants, which have been earlier reported in this extract ${ }^{[20]}$. It has already been reported that the medicinal properties of plants are conferred due to presence of these secondary metabolites like flavonoids, phenolics, essential oils ${ }^{[36]}$.

In vitro adhesions of $C$. albicans and $C$. glabrata were reduced to $50 \%$ in the presence of MES between $0.156-0.312 \mathrm{mg} / \mathrm{ml}$ concentrations. At $5 \mathrm{mg} / \mathrm{ml}$ of MES, the adherences of $C$. albicans and C. glabrata were reduced to 29.53 and $16.81 \%$, respectively (fig. 3A). MES reduced biofilm formation by C. albicans and C. glabrata in concentration-dependent manner (fig. 3B). Biofilm formation was reduced to $50 \%$ in C. albicans at a dose of $1.25-2.5 \mathrm{mg} / \mathrm{ml}$ of MES and in C. glabrata at $0.625-1.25 \mathrm{mg} / \mathrm{ml}$ of MES. MES at a concentration of $5 \mathrm{mg} / \mathrm{ml}$ reduced the biofilms of C. albicans and C. glabrata to $20-30 \%$.

This reduction in adhesion and biofilm formation of C. albicans and C. glabrata could be attributed to the presence of different secondary metabolites. Terpenes and terpenoids of different classes have been reported to reduce Candida biofilm in previous studies ${ }^{[37,38]}$. The leaf extracts of Stryphnodendron barbatimam, Equisetum arvense, Glycyrrhiza glabra and Punica granatum at a concentration of $50 \mathrm{mg} / \mathrm{ml}$, reduced C. albicans biofilm by $27,18,24$ and $26 \%$,

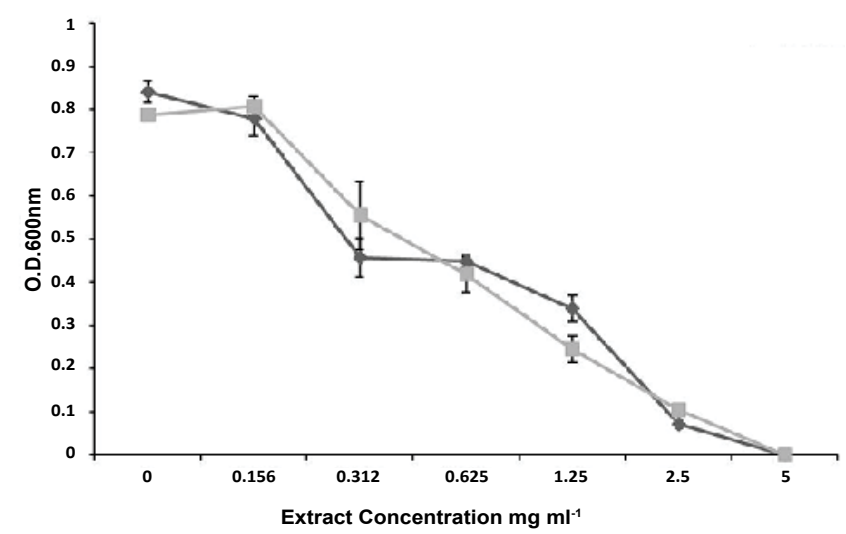

Fig. 1: Inhibitory effect of MES on C. albicans and C. glabrata Broth microdilution assay was performed at different dilutions of MES in YNB media against the cultures and growth was measured through optical density at $600 \mathrm{~nm}$ after $48 \mathrm{~h}$ incubation at $35^{\circ}$. MES is methanol extract of $E$. sphaericus leaves. - —C. albicans; - - C. glabrata 
A

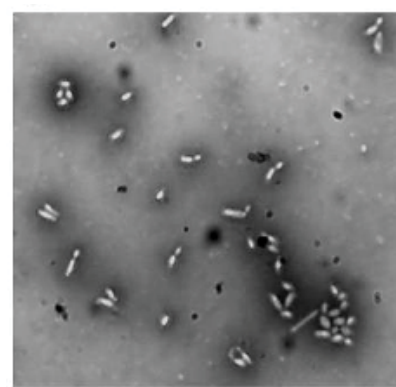

B

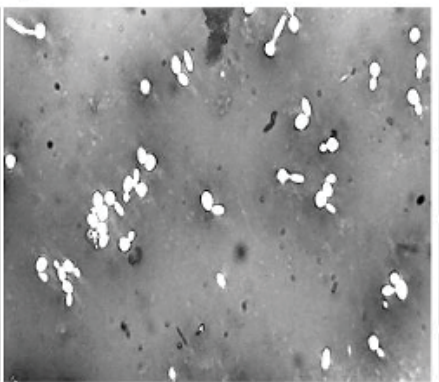

C

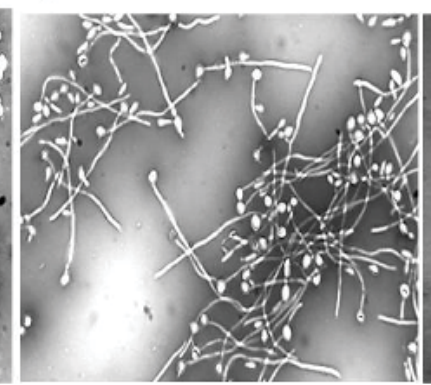

D

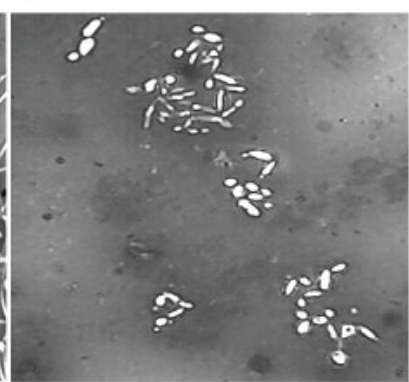

Fig. 2: Effect of MES on germ tube formation by $C$. albicans

Germ tube was induced by $10 \%$ serum in different tubes, with and without MES and photographs were taken after $4 \mathrm{~h}$ incubation at $37^{\circ}$. A. uninduced cells; B. uninduced cells with MES; C. induced cells; D. induced cells with MES. MES is methanol extract of E. sphaericus leaves.
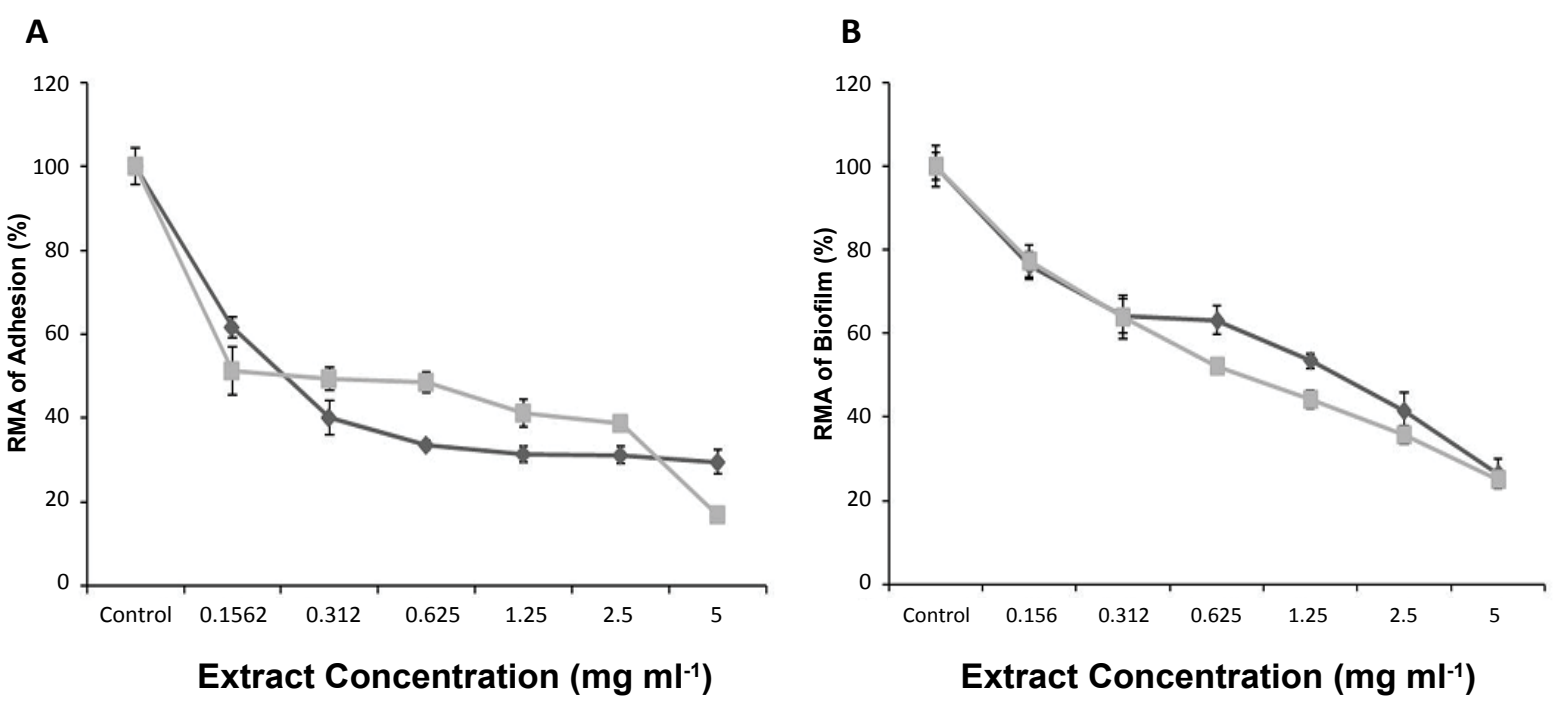

Fig. 3: Effect of MES on adhesion and biofilm formation by $C$. albicans and $C$. glabrata

Adhesion and biofilm formation was quantified by XTT assay and relative metabolic activities are shown at y-axis which are percent metabolic activities at different concentrations of MES, assuming $100 \%$ activity of the sample without MES. MES is methanol extract of $E$. sphaericus leaves - —C. albicans; - - C. glabrata

respectively ${ }^{[18]}$. The extract prepared in present study showed better result against $C$. albicans biofilm, when compared to previous reports.

This study has demonstrated anticandida properties of methanol extract of E. sphaericus leaves against plaktonic form, germ tube formation, adhesion and biofilm formation of two potent human pathogens, C. albicans and C. glabrata. These findings have further elaborated the medicinal value of E. sphaericus Roxb. that might help in translating the extract into a promising therapeutic agent to treat Candida infections.

\section{Acknowledgements:}

The authors thank the Graphic Era Deemed to be University, Dehradun for financial support. They acknowledge the support of the Head, and Dean Biotechnology, Graphic Era Deemed to be University and the Director, Defence Institute of Physiology and Allied Sciences, DRDO, Delhi. PG acknowledges the DST INSPIRE Fellowship. Authors also wish to thank Dr. K. Ganeshan, Senior Principal Scientist, IMTECH, Chandigarh for providing C. albicans strain SC5314 and Dr. Rakesh Mohan Painuli, Assistant Professor, Department of Botany, HNBG University, Srinagar for verifying the plant material collected. This work is a part of an Indian Patent 'A phytochemical rich herbal extract and the process of extraction thereof', filed vide application number Application No. 1625/DEL/2014 (Pub. No. WO/2015/193716, Dt. 23.12.2015; International App. No. PCT/IB2015/000950, Dt. 16.06.2015).

\section{Conflict of interest:}

Authors declare no conflict of interest. 


\section{REFERENCES}

1. Shao LC, Sheng CQ, Zhang WN. Recent advances in the study of antifungal lead compounds with new chemical scaffolds. Yao Xue Xue Bao 2007;42:1129-36.

2. Delaloye J, Calandra T. Invasive candidiasis as a cause of sepsis in the critically ill patient. Virulence 2014;5:161-9.

3. Sardi JC, Scorzoni L, Bernardi T, Fusco-Almeida AM, Mendes Giannini MJ. Candida species: current epidemiology, pathogenicity, biofilm formation, natural antifungal products and new therapeutic options. J Med Microbiol 2013;62:10-24.

4. Pfaller MA, Diekema DJ. Epidemeology of invasive mycoses in North America. Crit Rev Microbiol 2010;36:1-53.

5. Yapar N. Epidemiology and risk factors for invasive candidiasis. Ther Clin Risk Manag 2014;10:95-105.

6. Drug resistance, Threat report 2013. Available from: http:// www.cdc.gov/drugresistance /threat-report-2013/pdf/arthreats-2013-508.pdf.

7. Ramage G, Saville SP, Thomas DP, Lopez-Ribot JL. Candida Biofilms: an Update. Eukaryot Cell 2005;4:633-8.

8. Sudbery PE. Growth of Candida albicans hyphae. Nat Rev Microbiol 2011;9:737-48.

9. Sardi JC, Almeida AM, Mendes Giannini MJ. New antimicrobial therapies used against fungi present in subgingival sites-A brief review. Arch Oral Biol 2011;56:951-9.

10. Sofowara A. Medicinal plants and traditional medicines in Africa. New York: John Wiley and Sons; 1982. p. 256-9.

11. Hill AF. Economic Botany; a text book of useful plants and plant products. 2nd ed. New York: McGraw Hill Book Company; 1989. p. 127-9.

12. Guarrera PM, Forti G, Marignoli S. Ethanobotanical and ethanomedicinal uses of plants in distinct of Acquapendate (Lantinum, Cantral Italy). J Ethanopharmcol 2005;96:429-44.

13. Gupta R, Thakur B, Singh P, Singh HB, Sharma VD, Katoch $\mathrm{VM}$, et al. Anti-tuberculosis activity of selected medicinal plants against multidrug resistant Mycobacterium tuberculosis isolates. Indian J Med Res 2010;131:809-13.

14. Gupta P, Gautam P, Rai N, Kumar N. An emerging hope to combat Candida albicans: Plant based therapeutics. Biotechnol Res Int 2012;5:85-114.

15. Kumar G, Karthik L, Rao KVB. Antimicrobial activity of Elaeocarpus ganitrus Roxb.: an in vitro study. Bio Tech 2011;40:5384-7.

16. Sharma A, Joshi J, Kumar N. Antioxidant and antibacterial properties of leaves of Elaeocarpus sphaericus Roxb. and Pinus wallichiana from Uttarakhand region of India. Int J Green Pharm 2015;9:246-51.

17. Torey A, Sasidharan S. Anti-Candida albicans biofilm activity by Cassia spectabilis standardized methanol extract: an ultrastructural study. Eur Rev Med Pharmacol Sci 2011;15:87582.

18. de Oliveira JR, de Castro VC, das Graças Figueiredo Vilela P, Camargo SE, Carvalho CA, Jorge AO, et al. Cytotoxicity of Brazilian plant extracts against oral microorganisms of interest to dentistry. BMC Complement Altern Med 2013;13:208.

19. Costa GM, Endo EH, Cortez DAG, Ueda-Nakamura T, Nakamura CV, Filho BPD. Effect of plant extracts on planktonic growth and biofilm of Staphylococcus aureus and Candida albicans. Int J Curr Microbiol Appl Sci 2015;4:908-17.

20. Joshi S, Kumar N. GC-MS Analysis of the Phytoconstituents in the Methanolic Extract of Leaves of Elaeocarpus sphaericus Roxb. Int J Pharm Sci Rev Res 2015;35:103-7.
21. Dai J, Mumper RJ. Plant phenolics: extraction, analysis and their antioxidant and anticancer properties. Molecules 2010;15:7313-52.

22. Mamta, Mehrotra S, Amitabh, Kirar V, Vats P, Nandi SP, et al. Phytochemical and antimicrobial activities of Himalayan Cordyceps sinesis (Berk.) sacc. Indian J Exp Biol 2015;53:36-43.

23. NCCLS. Reference Method for Broth Dilution Antifungal Susceptibility Testing of Yeasts; Approved Standard. $2^{\text {nd }}$ ed. NCCLS document M27-A2, NCCLS: Pennsylvania, USA: 2002.

24. Bernardes I, Felipe Rodrigues MP, Bacelli GK, Munin E, Alves LP, Costa MS. Aloe vera extract reduces both growth and germ tube formation by Candida albicans. Mycoses 2011;55:257-61.

25. Gupta P, Nath S, Meena RC, Kumar N. Comparative effects of hypoxia and hypoxia mimetic cobalt chloride on in vitro adhesion, biofilm formation and susceptibility to amphotericin B of Candida glabrata. J Mycol Med 2014;24:169-77.

26. Gupta P, Meena RC, Rai N, Kumar N. Effect of hypoxia on in vitro adhesion, biofilm formation and antifungal susceptibility of Candida albicans. Int J Pharm Sci Rev Res 2015;32:279-83.

27. Kumamoto CA, Vinces MD. Contributions of hyphae and hypha-co-regulated genes to Candida albicans virulence. Cell Microbiol 2005;7:1546-54.

28. Geissman TA, Florkin M, Stotz E. Flavonoid Compounds, Tannins, Lignins and Related Compounds in Pyrrole Pigments, Isoprenoid Compounds and Phenolic Plant Constituents. In: Florkin M, Stotz EH, editors. Comprehensive biochemistry. New York, NY: Elsevier; 1963. p. 9-265.

29. Urs NVRR, Dunleavy JM. Enhancement of bactericidal activity of a peroxidase system by phenolic compounds. Phytopathology 1975;65:686-90.

30. Duke JA. Handbook of medicinal herbs. Boca Raton, Florida: CRC Press, Inc.; 1985.

31. Mason TL, Wasserman BP. Inactivation of red beet betaglucan synthase by native and oxidized phenolic compounds. Phytochemistry 1987;26:2197-202.

32. ScalbertA.Antimicrobial properties of tannins. Phytochemistry 1991;30:3875-83.

33. Dixon RA, Dey PM, Lamb CJ. Phytoalexins: enzymology and molecular biology. Adv Enzymol Relat Areas Mol Biol 1983;55:1-136.

34. Tsuchiya H, Sato M, Miyazaki T, Fujiwara S, Tanigaki S, Ohyama M, et al. Comparative study on the antibacterial activity of phytochemical flavanones against methicillinresistant Staphylococcus aureus. J Ethnopharmacol 1996;50:27-34.

35. Singh B, Chopra A, Ishar MP, Sharma A, Raj T. Pharmacognostic and antifungal investigations of Elaeocarpus ganitrus. Indian J Pharm Sci 2010;72:261-5.

36. Arif T, Mandal TK, Dabur R. Natural products: antifungal agents derived fromplants. In: Tiwar VK, Mishra BB, editors. Opportunity, Challenge and Scope of Natural Products in Medicinal Chemistry. Kerala, India: Research Signpost; 2011. p. 283-311.

37. Pemmeraju SC, Pruthi PA, Prasad R, Pruthi V. Candida albicans biofilm inhibition by synergistic action of terepenes and fluconazole. Indian J Exp Biol 2013;51:1032-7.

38. Raut JS, Chauhan NM, Shinde RB, Karuppayil SM. Terpenoids of plant origin inhibit morphogenesis, adhesion, and biofilm formation by Candida albicans. Biofouling 2013;29:87-96. 